\title{
A holistic approach for analysing the interoperability of a railway system
}

\author{
M. Jacyna \& J. Szkopiński \\ Faculty of Transport, Warsaw University of Technology, Poland
}

\begin{abstract}
This paper presents the main aspects concerning a systemic approach towards the problem of the interoperability of rail transport. Following a decision about the opening of the EU market and transport services for rail transport, the European Parliament and Council have introduced a number of safety and interoperability directives for implementing interoperability on the rail systems in the EU. Their goal was to integrate the rail transport systems, despite the differences in control-command and signalling systems, power supply and operation systems, ensuring that they are safe and do not disrupt the running of trains in different countries (with different infrastructure managers).

This paper indicates the main areas in the railway system which strongly depend on interoperability implementation.

Keywords: railway, the market rail service, interoperability, technical compatibility, operational conditions, allocation of routes, NPV, TSI.
\end{abstract}

\section{Introduction}

Interoperability has many meanings, depending on the discipline in which it is applied. It basically means the active participation in the ongoing process to ensure that the systems, procedures and culture of the organization are managed in such a way as to maximize opportunities for the exchange and re-use of information, both internally and externally. The concept of interoperability has emerged as a result of increased customer expectations with regard to the compliance of devices and systems in order to increase the availability and attractiveness of the product. Generally, interoperability is defined as: a property of a product or system, whose interfaces are completely understood, to work with other products or systems, present or future, without any restricted access or implementation. 
Interoperable adj. - able to operate in conjunction (Concise Oxford Dictionary).

In rail transport, the concept of interoperability appeared along with the implementation of European Directives relating to the establishment of the rail market and the increase in the possibility of the transfer of transport by rail between countries in the European Union [1]. Implementation of this idea, however, is charged with exceptional complexity and difficulty, specific to each country.

Although these systems have the same goal, i.e. the movement of people and goods, they are organized in a variety of different administrative, legal and technical conditions (other command control-commands, signaling systems, traction power supplies, gauge, etc.). Measures taken to eliminate the differences became the primary order and integration of "individual" railway systems need to fulfil the requirements of interoperability for the rail system.

The definition of interoperability, in railway terminology, is given in Directive 2008/57/EC [1], as follows: "Interoperability means the ability of a rail system to allow the safe and uninterrupted movement of trains which accomplish the required levels of performance for these lines. This ability depends on all the regulatory, technical and operational conditions which must be met in order to satisfy the essential requirements".

\section{Implementation of interoperability}

An accession between the members of the European Union commits each country to transpose the provisions of European Union directives and regulations to its national law. The creation of a rail market and rail transport services was implemented under the directives and regulations of the Commission and the European Council, and one of the most important, legally speaking, was the Directive No. 2008/57/EC. The so-called "Interoperability Directive" regulates the records of the integration of railway networks in EU countries directly to the implementation of the essential requirements of interoperability.

On the basis of this Directive, by decision, the European Commission published the Technical Specifications for Interoperability (TSI); this acts to determine conditions when a railway line (structural subsystems) satisfies the requirements of interoperability.

According to Directive No. 2008/57/EC (Art. 20), the implementation of interoperability can be successively performed. By duty of meeting the essential requirements, the TSI are always considered in the case of upgrading a line, taking into account traffic conditions and the financial and economic effects of this investment.

The "Directive" refers to a Trans-European Transport Network (TEN-T) railway lines on which the implementation of the interoperability requirements are obligatory, however, until $1^{\text {st }}$ January 2015 each member of the EU could decide the geographical scope of implementation of TSI outside the TEN-T lines. 
This facility has been beneficial to the Republic of Poland.

While international obligations relate to the TEN-T corridor, as well as the fact that the co-investment by the EU indicates the obligation for the implementation of interoperability, the lines outside of the TEN-T corridors are often funded by domestic sources, until $1^{\text {st }}$ January 2015 it was not obligatory to implement the TSI requirements.

Interoperability is implemented to align the relevant essential requirements of the following subsystems: rolling stock, infrastructure, energy, command controlcommand and signaling and signaling (track-side or vehicle's board). These changes also include functional aspects such as operation, maintenance and telematics for passenger and freight services.

This range of changes throughout all rail systems is a source of risk disturbance for the existing transport system and reduces the possibility of causing any disposal and allocation of funds for modernization and renewal of infrastructure.

Taking into account the essential requirements for each subsystem cause the wider range of construction works than was previously conducted, as well as obtain the appropriate verification of the subsystem with the essential requirements of interoperability and compatibility between railways subsystems.

The introduction of a new kind interoperability for trains, based on common European principles for the command control-command, signaling and supervision of railway traffic, as well as a change in the terms and conditions of entry into the service of vehicles, structures and devices, creates a basis of harmonized standards and TSI. There is no doubt, therefore, that the implementation of interoperability for railways is a process which will have an impact on the functioning and shaping of the rail transport system.

West Europe has knowledge and experience of this process of implementation of interoperability requirements on the lines located in the TEN-T corridors. There were issues based on monitoring subsystems after their modernization and there also some technical problems with interlocking devices and systems of the same kind and class because they were produced by different manufacturers and so were not fully compatible.

Periods when the system is changing from an existing to a fully compliant system with interoperability is called "system migration". According the TSI, migration is a necessary period for the smooth adjustment of a railway system by modifying the subsystems and components of the railway at the time of any modernization of infrastructure. separate periods of time are allocated in the TSI for each subsystem and range from a few to ten years (to 2021).

Following the decision of the European Commission, the executive body ERA (European Railway Agency) - has implemented measures to create a common database RDD filled the national technical requirements in order to meet the interoperability of the rail system, according to placing vehicles or devices into service on the railway lines.

ERA initiated and moderated the meeting of Railway Safety Authorities (NSA) of the EU countries, the so-called "Cross Acceptance" meetings, which sets up the possibility of mutual recognition of standards and regulations, together with the classification for the individual parameters: A - not required to verify, 
$\mathrm{B}$ - required test until clarify discrepancies, changes to certain national standards and $\mathrm{C}$ - always required examinations and tests with given the nature of the railway infrastructure of the country.

\section{Railway interoperability in Poland}

Transposition requirements of the interoperability directive for Polish law are contained in the Railway Legal Act (Article 4) [3], where it is indicated that the interoperability of the rail system is the ability of a rail system to allow the safe and uninterrupted movement of trains, meeting the technical, operational and legal conditions, ensuring compliance with the essential requirements of the interoperability of the rail system and enabling the efficient movement of the transEuropean rail network.

Following this definition, the interoperability of the rail system comprises basically three aspects: the continuous movement of trains, to ensure the safety and efficiency of train movement on the TEN-T lines and the fulfilment of the essential requirements. According to Section 4a of the Railway Legal Act [3] the scope of interoperability has been extended to almost the entire railway network in Poland. Exceptions apply organizationally, to separate lines, private lines, or those dedicated only to passenger transport in urban or suburban areas (as in the Act).

Differences in rail systems depend on the fundamentally different characteristics of the infrastructure, power supply, control-command and signaling systems. For this reason, international trains shall be considered and approved for use in any railway system individually. The same situation applies to vehicles and other devices produced and used in one country in the event of release to service in the other country - they call for additional research and testing.

Considering the changes in the administration area there should be emphasis on the role it plays within the National Rail Safety Authority (NSA) - in Poland the Office of Rail Transport (UTK), which has the power to issue: certificates for devices, structures and railway vehicles, safety certification for managers and railway undertakings, certification for drivers, as well as the authorization for placing in service of structural subsystems as infrastructure, energy, commandcontrol-command and signaling and signaling, and rolling stock.

The President of UTK, as the government authority, has the power over control-command, signaling and supervision, as well as the railway infrastructure, infrastructure managers, railway undertakings, and the ability to authorize and control-command and signaling the authorized and notified bodies.

UTK also oversees the implementation of the requirements of interoperability on the Polish railway network. In relation to their function, it may issue permits for subsystems complying with the requirements of interoperability, can dictate the implementation of interoperability in the case of the investments modernization of the railway line, as well as granting a derogation from the requirements of interoperability, in particular the application of the requirements of the TSI. 
Changes in the technical area and any assessment of the conformity of the devices and structures or railway vehicle is carried out by notified bodies. Their task is comprehensive and requires the harmonization of the standards, rules and limits, as indicated in each TSI.

The verification subsystem, in accordance with specific modules (operating procedures) is carried out from the design stage up to execution. During the procedure for verification of the subsystems, they are also analyzed for interoperability and suitability of their application.

The aim of the evaluation procedure is to prepare a declaration of EC verification of the subsystem and begin application to the UTK in order to obtain authorization for the structural subsystem.

The UTK has issued the first control-command EC certificate to operate ETCS system Level 1 in Poland.

In terms of changes in organizational structures, the transport and management of investment projects are important resources and the time needed to adjust the rail lines and rolling stock to interoperability must be on a scale which allows for maintaining the coherence of the railway network.

Given that the railway network in Poland is set across almost $20,000 \mathrm{~km}$ of railway lines, of which $6500 \mathrm{~km}$ of those lines are covered by the TEN-T, it is important to use the proper strategy and the evaluation of the allocation of funds to adapt the line to interoperability for its modernization.

The estimations of costs is made assuming that adapting the requirements of interoperability on the railway lines is located only in the corridors TEN-T. An approximate valuation of the index cost adjustment for $1 \mathrm{~km}$ line of 1.5 million, in total, amounts to more than 9 billion euros, which is a significant amount within the budget of the county, even taking into account the perspective of migration of structural subsystems to 2021 .

\section{Interoperability areas of implementation}

According to the definition of interoperability given in section 1, the adjustment of the railway line to interoperability is made to adapt all the devices and structures on the railway, their functions, and technical and operational parameters related to running and securing the moving train. The system consists of the following three structural subsystems: infrastructure, energy and control-command and signaling (track-side) devices needs to be adapted to the essential requirements in TSI.

Also, the interests of the many stakeholders within the rail transport system must be taken into account, among which, the following stand out:

1) Infrastructure manager - responsible for the structural subsystems.

2) Railways undertakings - funds disposal to transport people and/or cargo.

3) Customers - passengers or entities for which trucking is implemented.

4) Producers - manufacturers of railway devices, systems and vehicles.

This means that the goal of interoperability is a fairly complex decision problem involving three basic areas that need clarification.

The first area of interoperability for the uninterrupted movement of trains is understood as the realization of the assumed path of a train, with a stop only for 
the purpose of preconceived commercial operations (stop at the station for the needs of embarkation and disembarkation of passengers, cargo for a freight train, etc.). The train should not be stopped as a result of changes in the power supply system, control-command and signaling system or administrative boundary (state) within the EU community.

The second area of efficiency of the vehicle is connected with the high-capacity line and even anticipates high fluency of train traffic [4].

In this case, the probability of train delays must be sufficiently low so as not to effect the "headway time". Trains have mutual negative impacts, causing unintended vehicle speed reduction, and even the stopping of a train. In contrast, a basic condition for the interoperability of the system is the behaviour of the level of safety while the vehicle is moving by rail between rail systems [5].

Permission to use a type of railway vehicle, devices or systems, requires testing and field tests on the railway network. A positive evaluation of the technical and operational parameters on a single rail network cannot necessarily be transferred to other rail networks. To achieve consistency here, a common technical framework was established (TSI) [5-13], as well as the rules of risk assessment when alternative solutions and technical standards are used [14].

The final aspect concerns the essential requirements, including a change in technical and legal operations [1]. The essential requirements are classified into the following categories: safety, reliability, availability, health, environmental protection, technical compatibility, maintenance and operation. Compliance with the essential requirements is a prerequisite for admission to the operation of structural subsystems such as infrastructure, energy, control-command and signaling (track-side devices), control-command and signaling (on-board devices) and rolling stock.

In addition, well separated, functional subsystems such as operational systems, maintenance systems and telematics applications for passengers and freight services, including the interoperability constituents which group components, subassemblies, and full assemblies of hardware are included or are to be incorporated into a subsystem, upon which directly or indirectly depends on the interoperability of the system.

\section{Determinants introduction of interoperability}

The implementation plan for interoperability of the network depends mainly on obtaining answers to the following questions:

1) How do we determine a plan of modernization for railway lines in order to adapt them to the requirements of interoperability, taking into account the importance of the railway line, railway network consistency and the availability of financial resources?

2) How do we determine if the line is adapting to the requirements of interoperability, or whether this condition should be excluded?

International commitments regarding the TEN-T corridors and international freight corridors indicate the lines which should be a priority in the implementation plan for interoperability. In addition, the TSIs are dedicated to railway lines 
located in the corridors of the TEN-T, particularly defining how to conduct the migration of structural subsystems and what the time frames are for the full application of TSI (for Infrastructure and Energy, 2021).

Because, in the case of railway lines located outside the TEN-T, there is no clear interpretation of the legal and technical requirements as the timing and scope of the implementation of the interoperability, it is necessary to identify those factors that enable them to determine the priority of individual railway lines, taking into account adaptation to the requirements of interoperability for the entire rail network.

Such factors are closely related to the modalities provided for in the Directive 2008/57/UE and TSI. Basically, in order to evaluate a railway line, the following aspects should be considered:

1) Membership of the railway corridor TEN-T;

2) Estimated demand for interoperable trains on the railway line;

3) Co-financing of the modernization of the railway line from the EU;

4) The economic effect resulting from the difference in revenue resulting from the size of the number of interoperable trains for passenger and freight traffic to the costs arising from the modernization and adaptation to the requirements of interoperability line.

Taking into account national circumstances, the type of surface (truck bed), including the traction power network and control-command and signaling devices, it can be concluded that, although the structural subsystems of infrastructure and energy do not require significant changes, the control-command and signaling subsystem (track-side) requires a new, expensive ETCS system (and GSM-R).

Therefore, if the lines are located in the corridors of the TEN-T, upgrading of these subsystems may be "easier" to implement, whereas installing ERTMS outside TEN-T corridor can give rise to serious doubts.

In this context, there are questions about the economic justification for such changes, and the analysis does not indicate the demand for interoperable trains on railway lines.

Furthermore, it is also difficult to expect a positive NPV, i.e. the advantage benefits over costs for the investment in a given time.

Railway undertakings pursuing traffic on this rail line may not be interested in investing in interoperable rolling stock. For this reason, adjusting the line to interoperability cannot justify the financial effect on the railway line, undermining the whole point of the allocation of funds for its reconstruction.

Such considerations provoke reflection on the assessment of the determinants of railway lines (not belonging to the TEN-T), in terms of adapting them to the requirements of interoperability. For such lines, the following restrictions can be indicated:

\section{1) Appropriate transport offer for interoperable trains}

Limitation in the minimum number of interoperable trains forming the transport system - attractive from the point of view of the passenger's travel time or the frequency of this service. Given that the interoperable trains, in the stricted sense of definition, should not be detained in cases other than for the purposes of 
commercial activities, they should obtain the shortest time possible for maximum travel speed.

Obtaining the correct frequency of services mean as the ability to secure routes for interoperable trains at different times of the day. If we take into account the fact that the interoperable train moves at a distance greater than the local trains, and thus the travel time between a start and end station can take more than a few hours, even distribution of time intervals in the scope of train paths can increase the attractiveness of the service.

The above benefits relate basically to the Railway Undertakings that will have the incentive to invest in interoperable rolling stocks, as well as to the use of data on the rail line.

\section{2) Justifications for the economic modernization of the line}

Limitations of economic efficiency should be considered from the point of view of financial benefits for commercial lines (outside the TEN-T). This is a different point of view in relation to the "corridor", where the benefits must also be considered in a wider scope and scale, among others taking into account social, environmental and political considerations.

In order to determine the economic constraints, they should be analysed and compared to the expected number of interoperable trains on the line, the retraining of existing trains on interoperable trains, the creation freight and passenger streams, etc. This increase may be due to the benefits of revenues from the provision of routes, reducing operational costs. On the other hand, the question of the size of the necessary financial resources for the change in the structural subsystems, in particular the implementation of the type ERTMS system.

Analysis of the size required to incur capital expenditures should take into account relevant aspects of traffic and operation, obtaining the minimum headway time between trains, a buffer time to compensate primary delays and delays transmitting to other trains, for the adequate flow of traffic on the railway line.

The economic effect will therefore be a difference between the benefits of the minimum number of interoperable trains running on the line and the minimum cost necessary to keep the requirements of interoperability.

\section{3) Introducing additional interoperable trains}

Limited in the capacity of the railway line is defined as the maximum achievable number of additional interoperable train routes with the introduction of an appropriate buffer time "window" for existing trains reclassified into interoperable trains.

The maximum value can be determined on the basis of the density of train paths and the probability of negative impacts as a result of the emergence of deviation from the train running on its scheduled route.

\section{4) The terms for interoperable trains and the buffer time "coining" train routes} in the existing timetable

Limitation in buffer time depends on a long distance of interoperable trains and froms the requirement of its "undisrupted" movement. If the course of an interoperable train is taken into account, consisting of several sections of the railway line, passing over different railway nets (infrastructure managers), as well 
as movement disorders generated at junctions, it is necessary to conduct a temporary buffer time for interoperable trains so that the train can be moved in accordance with the scheduled route along with avoiding collisions with other trains when they move from one line to the other one.

The "window" time can be interpreted as the time dilatation (time implications of the train increased by extra time), allowing the suppression of interference by the absorption of the primary delays train to a scheduled time for the next train routes.

It remains to be determined how much the time dilatation should be and how many train routes will be altered as a result of the emergence of the initial disturbance. Such analysis requires examination and evaluation of the distribution of train paths, for a whole day or in the rush hour.

An important question remains: is the intensity of train applications, as well as the time of their "service", a shifted exponential distribution or based completely on random phenomenon?

Such an assessment seems to be able to be made after examining the correlation between the existing and interoperable trains paths.

The above-mentioned restrictions specify the possibility of obtaining a maximum movement of trains with the involvement of interoperable trains with the fluency of their running services and the possibility for the absorption of any primary delays.

On the basis of the priority issues that have been defined, we can develop a model for the assessment of railway lines in adapting to the requirements of interoperability.

As a result, it will be possible to develop a list of railway lines, compiled chronologically according to their priorities, for the implementation of interoperability.

\section{Conclusions}

Opening the railway market for services in the EU requires the implementation of the interoperability conditions, to integrate railway systems and enable the movement of passenger and freight trains without unnecessary restrictions arising from the technical and organizational differences in these systems.

Allowing access of interoperable trains to interoperable networks is preceded by activities that allow the assessment of the fulfilment of all basic conditions in terms of technical compatibility, performance, and organization of the trains.

The requirements above are regulated by the European Union - in particular, Directive No. 2012/34/UE (concerning the allocation of routes), No. 2004/49/UE (concerning railway safety) and No. 2008/57/EC (concerning the interoperability of the rail system).

Although almost all of the requirements have been formulated and given in the documents of the EU regulations (including TSI), questions relating to the allocation of routes on lines (outside the TEN-T corridors) can be a problem, due to the different technical characteristics and movements, different categories and 
levels of infrastructure maintenance, a significant share of the capacity of the railway passenger and freight trains (local traffic), etc.

Due to the weight of evidence for problems in the implementation of interoperability, it seems necessary to carry out an in-depth assessment of the chronology and scope of the implementation of interoperability of railway networks. This requires the development of a simulation model, which is based on various terms of cost and benefits, and is based on the constraints arising from the decision-making of individual stakeholders within the transportation system, which will allow for the multivariate representation of the different possibilities of the process of migration of the railway system to its interoperability.

\section{References}

[1] Directive of the European Parliament and of the Council 2008/57/EC of 17 June 2008, "on the interoperability of the rail system within the Community", Acts. OJ L 191 from 18.7.2008.

[2] Directive of the European Parliament and of the Council 2004/49/EC of 29 April 2004, “on safety on the Community ...", Coll. OJ L 164, from 30.4.2004.

[3] MT, BIGM, "Railway Transport Act of 28 March 2003”, Coll. Laws 2011, No. 233, item. 1381.

[4] Woch, J.: General approach to problems of bandwidth as a problem of dimensioning systems rail, Warsaw 1977.

[5] Commission Recommendation, 29 March 2011, "the authorization for placing in service of structural subsystems and vehicles under Directive of the European Parliament and of the Council 2008/57/EC", Coll. OJ L 95 from 8.4.2011.

[6] EU Commission Decision No 2008/163/EC of 20 December 2007, "Technical specification of interoperability relating to 'safety in railway tunnels' in the trans-European conventional rail system and the transEuropean high-speed rail", Coll. OJ L 64 from 7.3.2008.

[7] EU Commission Decision No 2008/164/EC of 21 December 2007, "Technical specification for interoperability relating to 'persons with reduced mobility' in the trans-European conventional rail system and the trans-European high-speed rail", Coll. OJ L 64 from 7.3.2008.

[8] EU Commission Decision No 2011/275/EU of 26 April 2011, “Technical interoperability relating to the 'infrastructure' trans-European conventional rail system", Coll. OJ L 126 from 14.5.2011.

[9] EU Commission Decision No 2011/274/EU of 26 April 2011, "Technical specification for interoperability relating to 'Energy' trans-European conventional rail system", Coll. OJ L 126 from 14.5.2011.

[10] EU Commission Decision No 2011/291/EU of 26 April 2011, "On the technical interoperability relating to the 'subsystem rolling stock locomotives and passenger rolling stock' the trans-European conventional rail system", Coll. OJ L 139 from 26.5.2011. 
[11] EU Commission Decision No 2011/314/UE of 12 May 2011, "the technical specification for interoperability relating to the subsystem 'Traffic Operation' trans-European conventional rail system”, Coll. OJ L 144 from 31.5.2011.

[12] Commission Regulation (EU) No 328/2012 of 17 April 2012, “technical specification for interoperability relating to the 'telematic applications for freight' trans-European conventional rail system”, Coll. OJ L 106 from 18.4.2012.

[13] Commission Regulation (EU) No 454/2011 of 5 May 2011, “concerning a technical specification for interoperability relating to the 'subsystem telematics applications for passenger services' of the trans-European rail system", Coll. OJ L 123 from 12.5.2011.

[14] Commission Regulation (EC) No 352/2009, "on the adoption of a common safety method for assessing the valuation and risk assessment", Coll. OJ L 108 from 29.4.2009.

[15] Regulation of the Minister of Transport, Construction and Maritime Economy of 2 May 2012, "Interoperability of the rail system", Coll. Laws 2012, pos. 492.

[16] Białoń, A., Gradowski, P., Gryglas, M.: An outline of the method of analysis of the impact of ERTMS/ETCS on the growth capacity of railway lines, Publishing House of Warsaw Technical University, Warsaw, 2011.

[17] EU Commission Decision No 2012/88/UE of 25 January 2012, "the technical specification for interoperability relating to the 'subsystem' Control-command and signaling rail system”, Coll. OJ L 51 from 23.2.2012.

[18] Jacyna M.: Selected aspects of modeling transport systems, Publishing House of Warsaw Technical University, Warsaw 2009.

[19] Jacyna M.: Modelling and evaluation of transport systems. Warsaw University of Technology Publishing House, Warsaw 2009.

[20] Jaspers: "The Blue Book. The rail sector. Infrastructure and rolling stock", September 2008.

[21] PKP PLK SA, "National Implementation Plan of the European Rail Traffic Management System in Poland" - a document adopted by the Council of Ministers on 6 March 2007.

[22] Work edited by Marianna Jacyny, Polish Logistics System. Determinants of technical and technological co-modality of transport, Publishing House of Warsaw Technical University, Warsaw 2012.

[23] European Commission - DG TREN, "Traffic flow: Scenario, Traffic Forecast and Analysis of Traffic on the TEN-T, Taking into Consideration the External Dimension of the Union. Final Report", 14th December 2009 Co-ordinator: Tetraplan A/S. 